https://doi.org/10.12913/22998624/120928

\title{
Empirical Tests of Stress in Gyroplane Rotor During Flight
}

\author{
Jacek Czarnigowski ${ }^{1}$
}

1 Katedra Termodynamiki, Mechaniki Płynów i Napędów Lotniczych, Wydział Mechaniczny, Politechnika Lubelska, ul. Nadbystrzycka 36, 20-618 Lublin, Poland, e-mail: j.czarnigowski@pollub.pl

\begin{abstract}
The paper presents the results of experimental investigations of total tensile stresses in a gyroplane's rotor during flight. The research aimed to determine which flight maneuvers induce the greatest stress in the rotor blade and the hub bar. The object of research was an ultralight gyroplane Tercel by Aviation Artur Trendak equipped with a rotor by the same manufacturer. Measurements were taken a) at the root of the rotor blade in the longitudinal direction, at the rotor blade's lower surface in the point where the blade is attached to the hub bar, and b) in the hub bar, on its lower surface also in the longitudinal direction. To measure the stress, the author constructed an original measuring system based on the strain gauge bridge circuit mounted on the rotor head. The tests were carried out in a wide range of maneuvers within the gyroplane's flight envelope. The highest value of tensile stress was found to occur while rapidly reducing the horizontal velocity in steep descent.
\end{abstract}

Keywords: gyroplane, rotor blade, hub bar, stress.

\section{INTRODUCTION}

Rotorcrafts are aircraft that generate lift by means of rotors instead of fixed wings [1]. Rotors are typically composed of two to six blades $[2,3]$ and are the elements that both keep the machine in the air and control the direction of its flight [2]. In the case of helicopters, they also generate thrust $[1,4]$. This means that the rotor blades are the key elements of the rotorcraft: their shape determines the flight performance as well as safety $[4 \div 10]$. Therefore, they are designed for aerodynamics $[4,6 \div 8]$ as well as strength $[6,11]$.

Aircraft certification procedures [12, 13] set requirements for rotors demanding, among others, that "Main rotor structure must be designed to withstand the ... critical flight loads" [13], and "Strength requirements are specified in terms of limit loads (the maximum loads to be expected in service) and ultimate load (limit loads multiplied by prescribed factor of safety)" [13]. Therefore, the values of loads on the rotor's structure must be defined. This is particularly important in developing new aircraft models $[14 \div 16]$.
It is the role of the design organization to determine the maximum loads acting on the rotor and the conditions when they occur. In the case of helicopters, there exists some body of literature that identifies the rotor loads (among others $[4,5,17,18])$. Experimental and numerical studies demonstrated that helicopter rotor blades are most heavily loaded in hover and during flight with maximum forward speed. Accordingly, the blades of the main rotor are tested for strength mainly in these conditions [7, 19].

However, the gyroplane rotor operates in a different way. In flight, it is unpowered and generates lift in autorotation. The rotor blades are thus subject to centrifugal forces (caused by the rotary motion of the blades) and aerodynamic forces of the air inflow to the rotor (caused by the movement of the aircraft) $[1,20,21]$. The rotor does not transfer the propulsive torque producing the thrust as it is in the case of helicopters [1], and thus the gyroplane cannot hover. A question arises, what flight conditions (which maneuvers) generate the highest loads on the gyroplane rotors. As no literature was found to provide the answer, the purpose of the research presented in this paper was to determine these conditions on the basis of experiments in flight. The 


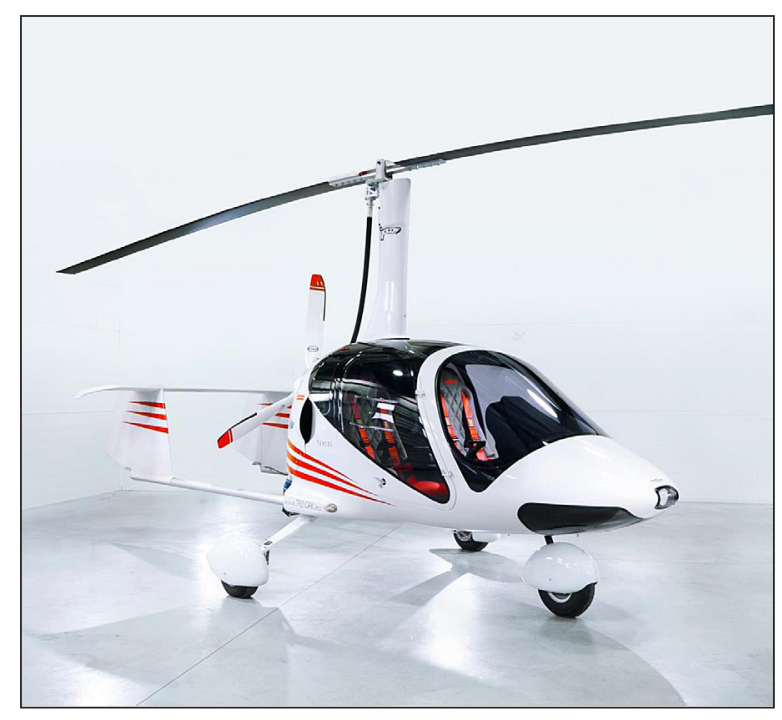

Fig. 1. Tercel gyroplane (courtesy of Aviation Artur Trendak)

tests followed the methodology presented in [5] and were modernized by applying digital measurement and data recording techniques.

\section{THE OBJECT AND SCOPE OF RESEARCH}

\section{The object of research}

The tests were conducted on a particular model of an ultralight gyroplane, Tercel by Aviation Artur Trendak, a two-seat machine in a side-by-side configuration (Figure 1). Its main structural component is a composite fuselage made of carbon fibre type Havel $160 \mathrm{~g} / \mathrm{mm}^{2}$ and carbon Kevlar Havel $165 \mathrm{~g} / \mathrm{mm}^{2}$ with a $2 \mathrm{~mm}$ Lantor Soric core with e-nova ma6325 vinylester resin. The hull is made by infusion. The keel is composed of a pair of slender aluminum beams. The vertical twin fins of the tail are the aircraft's vertical stabilizers and support the rudder. The horizontal stabilizer of a symmetrical section with winglets is mounted on top of the vertical fins. All these elements are composite structures. Tercel is powered by a CA 912 ULT engine (a Rotax 912 UL engine modified by Aviation Artur Trendak with an Iveco turbocharger). The aircraft is equipped with a three-blade composite Kaspar Aero 2/3 LT propeller of a manually adjustable pitch, and a rotor manufactured and balanced by Aviation Artur Trendak. Selected parameters of the aircraft are listed in Table 1.

The rotor is composed of two blades connected by a straight hub bar. The blades are made
Table 1. General characteristics of and performance of Tercel gyroplane

\begin{tabular}{|l|c|}
\hline \multicolumn{2}{|l|}{ Dimensions, weights and general data } \\
\hline Cockpit width & $1.36 \mathrm{~m}$ \\
\hline Fuselage width & $2.35 \mathrm{~m}$ \\
\hline Overall length (without rotor) & $5.04 \mathrm{~m}$ \\
\hline Overall height & $2.87 \mathrm{~m}$ \\
\hline Wheel diameter & $350 \mathrm{~mm}$ \\
\hline Empty weight & $295 \mathrm{~kg}$ \\
\hline Load capacity & $265 \mathrm{~kg}$ \\
\hline Maximum take-off weight & $560 \mathrm{~kg}$ \\
\hline Propeller & KASPAR Aero $2 / 3 \mathrm{~T}$ \\
\hline Propeller diameter & $1.72 \mathrm{~m}$ \\
\hline Rotor & Aviation Artur Tren- \\
\hline dak (aluminum)
\end{tabular}

Table 2. Characteristics of the rotor blade

\begin{tabular}{|l|c|}
\hline Airfoil type & NACA 8H12 \\
\hline Chord & $200 \mathrm{~mm}$ \\
\hline Rotor diameter & $8600 \mathrm{~mm}$ \\
\hline Angle of incidence & $5^{\circ}$ \\
\hline Material & $\begin{array}{c}\text { Aluminum EN } \\
\text { AW-6005A T6 }\end{array}$ \\
\hline Tensile strength $\mathrm{R}_{\mathrm{m}}$ & $276 \mathrm{MPa}$ \\
\hline $\begin{array}{l}\text { Proportional elastic limit with } \\
\text { an elongation of } 0.2 \% \mathrm{R}_{\mathrm{p} 0.2}\end{array}$ & $265 \mathrm{MPa}$ \\
\hline Elongation $\mathrm{A}$ & $8,8 \%$ \\
\hline
\end{tabular}

of extruded aluminum. Their hollow profiles have uniform cross-section and uniform angle of incidence along the whole length.

\section{Measuring system}

The tests were to determine the level of tensile stress at the most heavily loaded points of the blade and in the hub bar. For this purpose, 


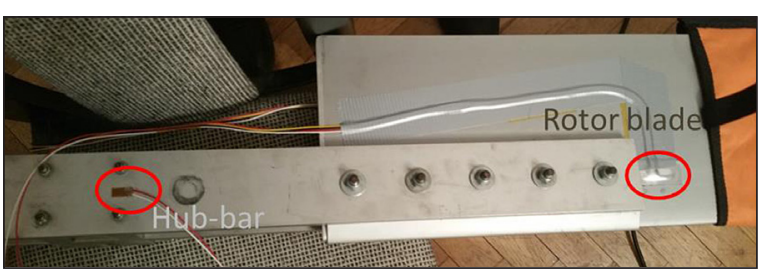

Fig. 2. Location of sensors

Tenmex TFs 10/350 strain gauges were used (technical data in Table 2), selected on the basis of the expected stress range and the range of resistance of the measuring system. In the case of the rotor blade, the strain gauge was fastened to its bottom surface, at the point located $5 \mathrm{~mm}$ from the edge of the hub bar in the neutral axis of the blade (i.e. in the line of screws that fasten the blade to the hub bar). The other gauge was attached to the bottom surface of the hub bar at the point located in the neutral axis of the rotor blade, $20 \mathrm{~mm}$ from the axis of rotation, as illustrated in Figure 2.

The measurements were taken by means of a circuit in a quarter-bridge configuration type II as presented in Figure 3. Identical strain gauges TFs10/350 were used as all resistors in the circuit:

- $\mathrm{R} 1$ as the active strain gauge to measure strain along the element in question,

- R2 as a passive resistor to complete the voltage divider circuit (dummy resistor) mounted in a close thermal contact with R1, but placed in transverse direction to the tensile strain, and not bonded to the element,

- R3 and R4 to complete the bridge.

This configuration of identical sensors helps minimize the effect of temperature changes on the results (the temperatures of the active and the

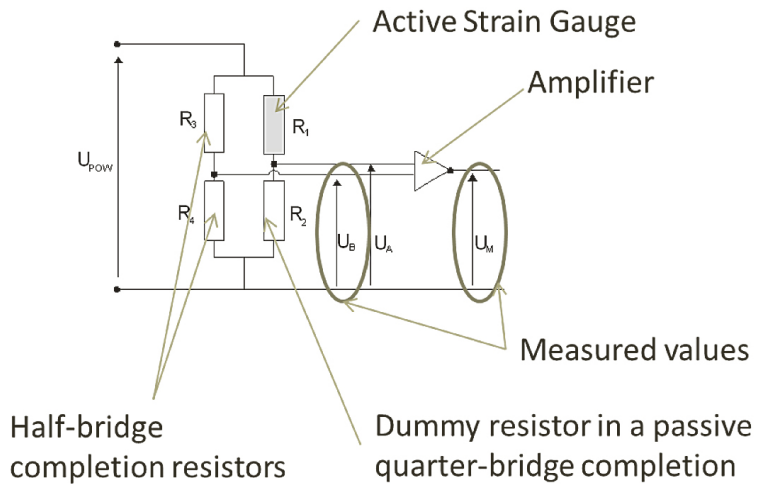

Fig. 3. Strain gauge configuration of the measurement system
Table 3. Characteristics of TFs10/350 sensor

\begin{tabular}{|l|l|}
\hline Resistance & $350 \Omega( \pm 0,2 \%)$ \\
\hline Gauge width & $4.6 \mathrm{~mm}$ \\
\hline Gauge length & $15.0 \mathrm{~mm}$ \\
\hline Gauge thickness & $60 \mu \mathrm{m}$ \\
\hline Operating temperature range & $-40 \div 200{ }^{\circ} \mathrm{C}$ \\
\hline Gauge factor (GF) & $2.1 \div 2.2( \pm 0.5 \%)$ \\
\hline $\begin{array}{l}\text { Temperature coefficient } \\
\text { of resistance (TCR) }\end{array}$ & $0.04 \times 10^{-3} /{ }^{\circ} \mathrm{C}$ \\
\hline
\end{tabular}

dummy gauges are deemed the same). Therefore, two values of $U_{B}$ and $U_{M}$ were measured.

The measurement system was equipped with a differential amplifier of the author's own design. The results were recorded by means of MSP-EXP430FR6989 evaluation module (Texas Instruments). The evaluation module was mounted on the hub bar directly above the teeter bolt of the rotor head (so in the rotor's axis of rotation), the amplifier was placed on one arm of the hub bar, and the measurement system's power supply (a lithium-ion battery: $1000 \mathrm{mAh}$, $9 \mathrm{~V})$ was located on the other arm. The reference strain gauges R3 and R4 were placed directly under the evaluation module. The signals were registered with a constant frequency of $10 \mathrm{~Hz}$ during the whole test flight.

The strain readings needed to be matched with the flight parameters. As the aircraft was not equipped with any navigation nor flight parameter recording system, an external device was used, namely the Garmin D2 Bravo pilot watch. The flight parameter records comprised: the flight altitude (measured on the basis of a pressure sensor with correction of base pressure with GPS), the ground speed (GPS-based), and the direction of flight (GPSbased), and were taken with the frequency of $1 \mathrm{~Hz}$. The flight parameter and the stress data streams were synchronized on the basis of a timestamp.

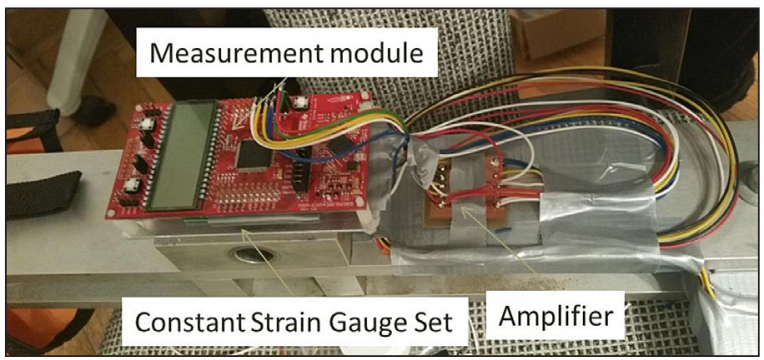

Fig. 4. The rotor head armed with elements of the measuring system 


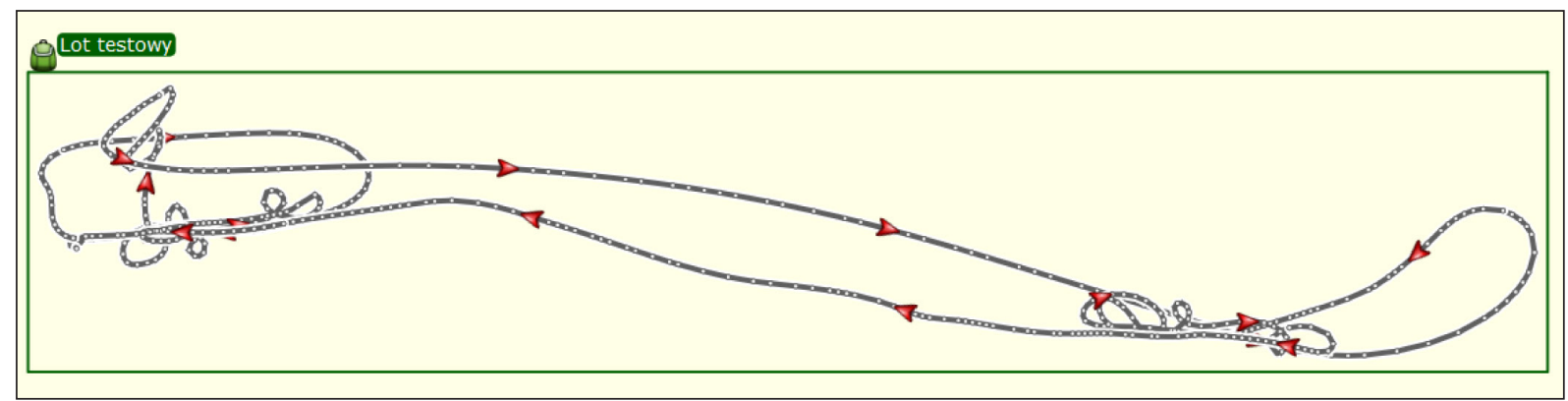

Fig. 5. Path of the test flight

\section{Test flight}

The tests flight was a loop (Figure 5) starting at Baranów airfield (N52 07 '19.5” E20²8'54.3”; Elevation: $295 \mathrm{ft}$;). It took place on March 1, 2017, courtesy of and in cooperation with the manufacturer of the gyroplane. The gyroplane was loaded to its maximum take-off weight of $560 \mathrm{~kg}$ (empty weight of the aircraft, two crew members, $100 \mathrm{~kg}$ of fuel, topped up with sandbags), what was confirmed by weighting the loaded machine (Figure 6). The total flight time was 26 minutes. The maximum altitude was $300 \mathrm{~m}$ and the flight speed up to $172 \mathrm{~km} / \mathrm{h}$. The air temperature was $8^{\circ} \mathrm{C}$, the air pressure $988 \mathrm{hPa}$, the maximum wind speed 0.2 $\mathrm{m} / \mathrm{s}$ in direction 340 . As the wind speed was very

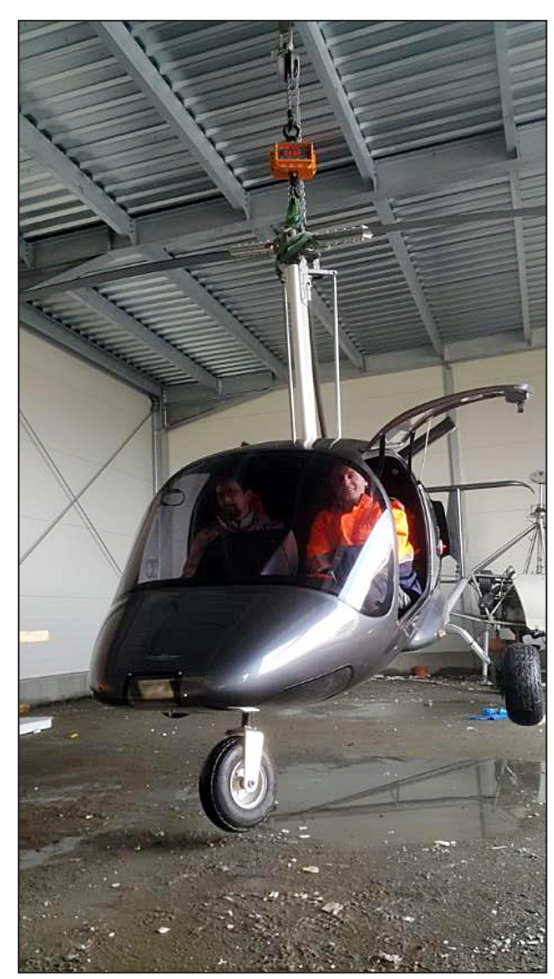

Fig. 6. Weighting the gyroplane low, the author assumed that the ground speed is close enough to the airspeed to treat them as equal. Therefore, further analysis rested upon the GPS-based ground speed measurement.

The assumption was to measure the rotor blade and hub bar stresses during a variety of typical maneuvers within the aircraft's flight envelope. The test flight included: engine warm-up, taxiing, prerotation, take-off, climb-out, maneuvers at different speeds including straight-andlevel flight with the maximum speed, climbs, descents, approach to landing, and landing.

\section{RESULTS}

Figure 7 presents the synchronized readings of the hub bar and rotor blade stresses and the flight parameters. In general, the rotor blade was subject to greater tensile stress than the hub bar: once in the air, the hub bar stress ranged from 45 to $92 \mathrm{MPa}$, whereas the rotor blade stress was between 68 and $121 \mathrm{MPa}$.

To determine which phase of the flight generated the highest tensile stress in the rotor, To determine which phase of the flight generated the highest tensile stress in the rotor, the author analyzed the individual maneuvers in detail.

Figure 8 shows the first 500 seconds of the test. The engine started in the $30^{\text {th }}$ second. The engine warm-up phase lasted until $260^{\text {th }}$ second (aircraft on the ground with the rotor still, hence the stresses are negligible, and the recorded fluctuations result from the vibrations of the aircraft caused by the engine operation). After the engine temperature reached the required level, the pilot taxied to the runway with a speed of about 20 $\mathrm{km} / \mathrm{h}\left(260^{\text {th }}-390^{\text {th }}\right.$ second of the test $)$. The aircraft movement along the bumpy surface of the grass airstrip generated oscillations of the rotor 

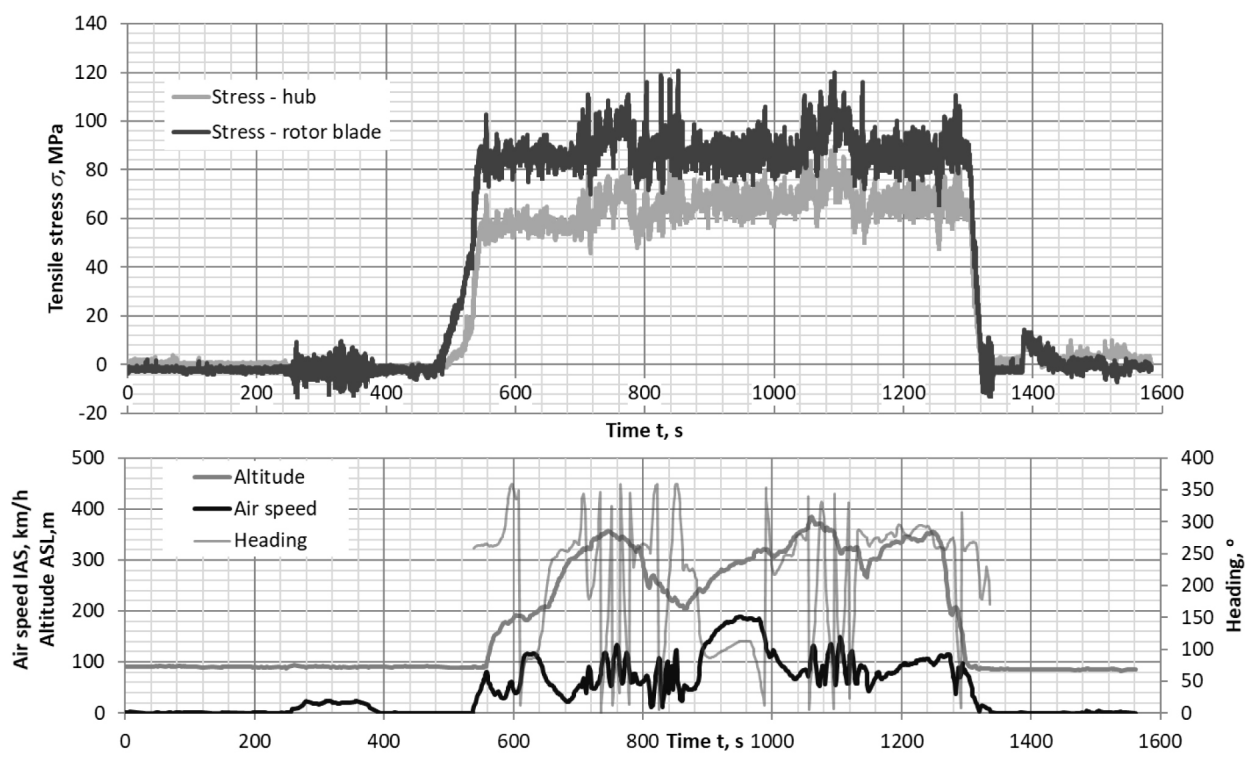

Fig. 7. Hub bar and rotor blade tensile stress and the flight parameters during the test

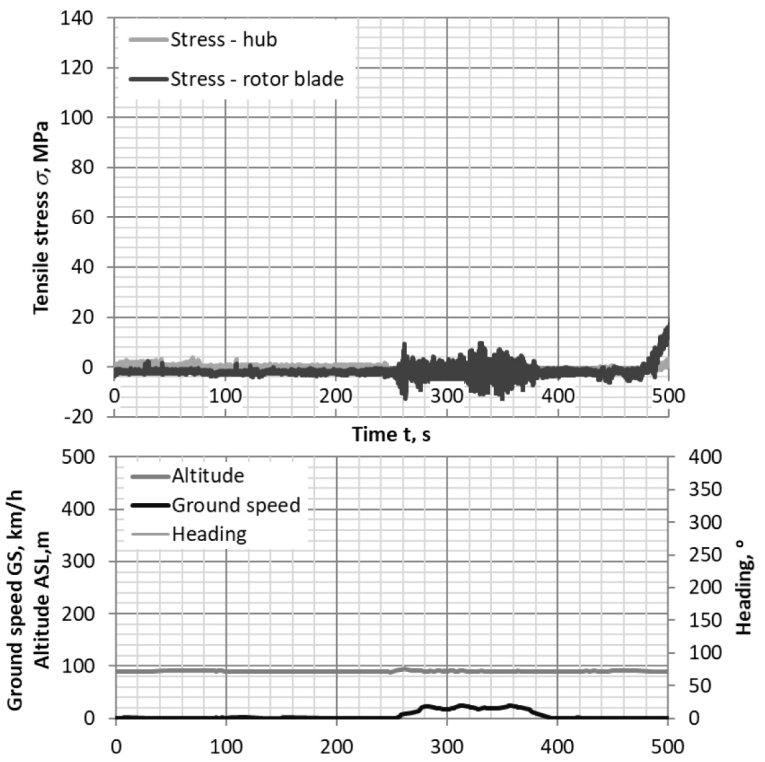

Fig. 8. Stresses against flight parameters at engine start, warm-up, and taxiing
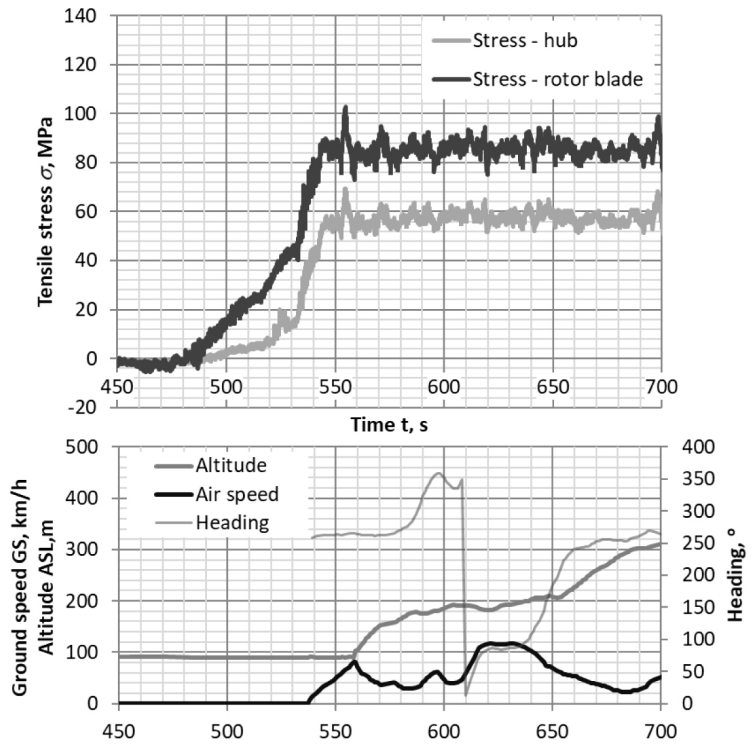

Fig. 9. Stresses against flight parameters at prerotation, ground roll, liftoff, climb and first turns

airplane did not change the position (warm-up, preparation for the start).

Figure 9 refers to the take-off phase. The prerotation took place between the $460^{\text {th }}$ and $537^{\text {th }}$ second of the test; the aircraft was standing at the beginning of the runway with the rotor, temporarily powered by the main engine, accelerating to about $210 \mathrm{rpm}$. This generated a stress of $45 \mathrm{MPa}$ in the rotor blade and $20 \mathrm{MPa}$ in the hub bar. Once the rotor speed reached the level of $210 \mathrm{rpm}$., the prerotator was disengaged and the ground roll to gravity. This was observable especially as the 


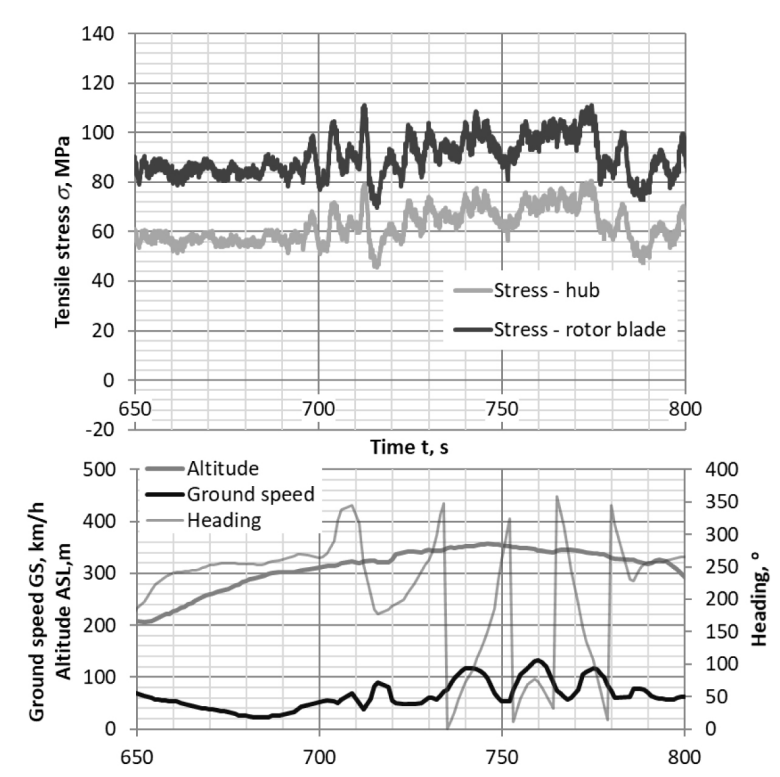

Fig. 10. Stresses against flight parameters at tight S-turns with changing speed
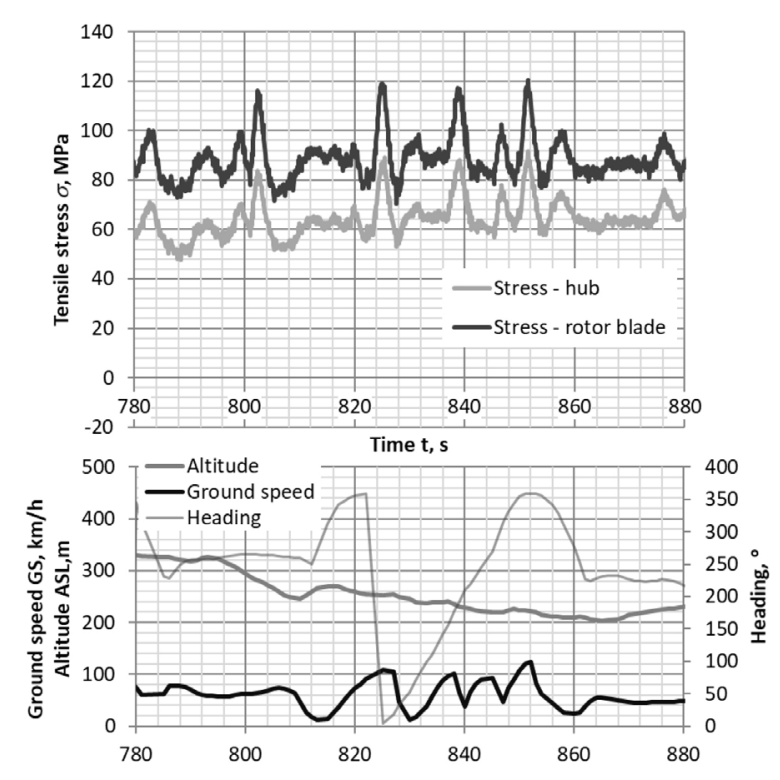

Fig. 11. Stresses against flight parameters at steep descent

the hub bar $(80 \mathrm{MPa})$, with the respective mean values of 94 and $69 \mathrm{MPa}$. As the pilot strived to keep the altitude constant, the loss of lift due to tilting of the rotor for turn resulted in the reduction of forward speed. During these maneuvers, the kinetic energy of the aircraft was used without a significant change in the kinetic energy of the rotor's rotation.

The maneuvers to follow resulted in strong fluctuations of the rotor stress. Between the $810^{\text {th }}$ and $860^{\text {th }}$ second of the test, the pilot reduced the forward speed by tilting the rotor rearward. This maneuver is used to descend steeply. Increasing the angle of attack in forward flight generates drag, and the effect is boosted by the airflow's increasing the rotor speed. Thus, the kinetic energy of the aircraft's forward flight is turned into the kinetic energy of the rotor disc.

The effect was reflected in changes of the rotor blade and hub bar stresses: a rapid increase of the angle of attack $\left(800^{\text {th }}, 823^{\text {rd }}, 837^{\text {th }}, 850^{\text {th }}\right.$ second of the test) resulted, with a two-second delay, in peaks of stress in the rotor blade (up to 120.6 MPa) and the hub bar (89.9 MPa). These 2 seconds corresponded to the time for building up the kinetic energy of the rotor disc. As the aircraft slowed down in its forward movement, the airflow acting on the rotor was reduced, decreasing the lift and the autorotation force. Thus, the kinetic energy of the rotor was consumed: the rotor speed decreased and the stresses dropped. 


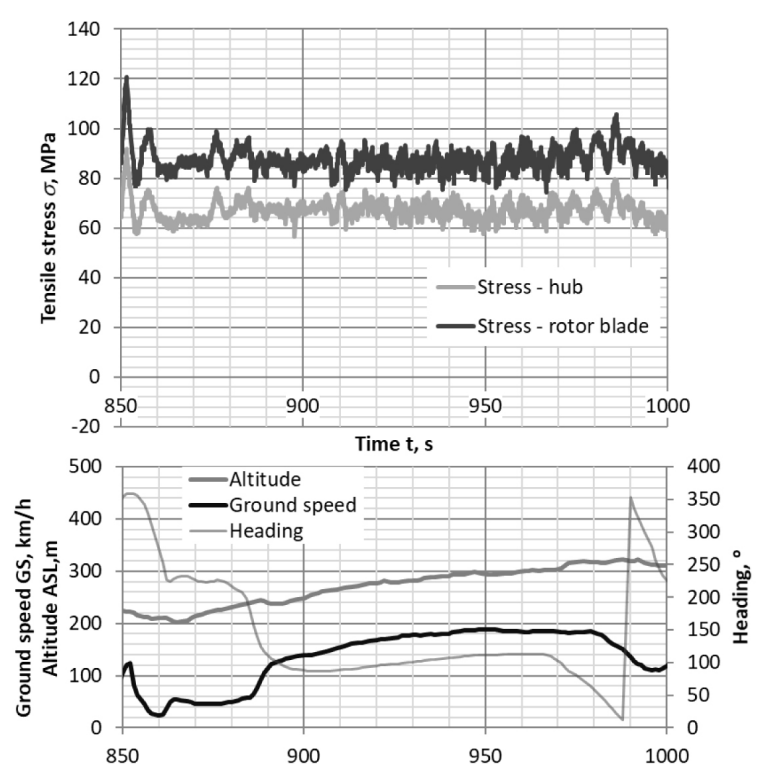

Fig. 12. Stresses against flight parameters at straight-and-level flight with maximum speed

The subsequent phase of the test was a gentle climb followed by a straight-and-level flight to reach the maximum cruising speed of $190 \mathrm{~km} / \mathrm{h}$ (the $880^{\text {th }}-970^{\text {th }}$ second of flight in Figure 12). The stresses remained relatively stable with the mean values of $87 \mathrm{MPa}$ for the rotor blade and 66 $\mathrm{MPa}$ for the hub bar. As for the maximum stress, it reached $105 \mathrm{MPa}$ in the blade and $82 \mathrm{MPa}$ in the hub bar. The forward speed practically does not influence the stresses in the rotor.

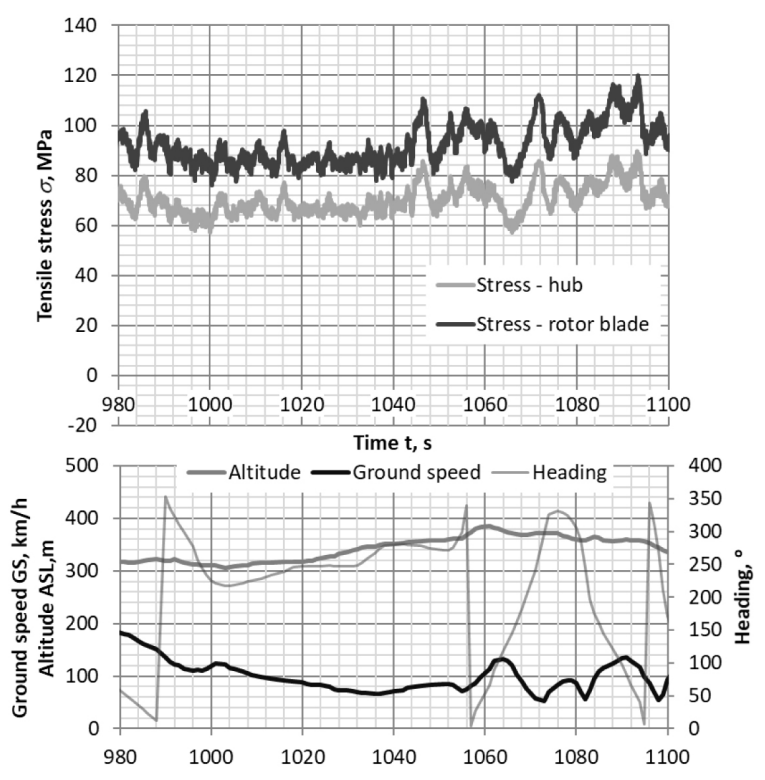

Fig. 13. Stresses against flight parameters at gentle turn

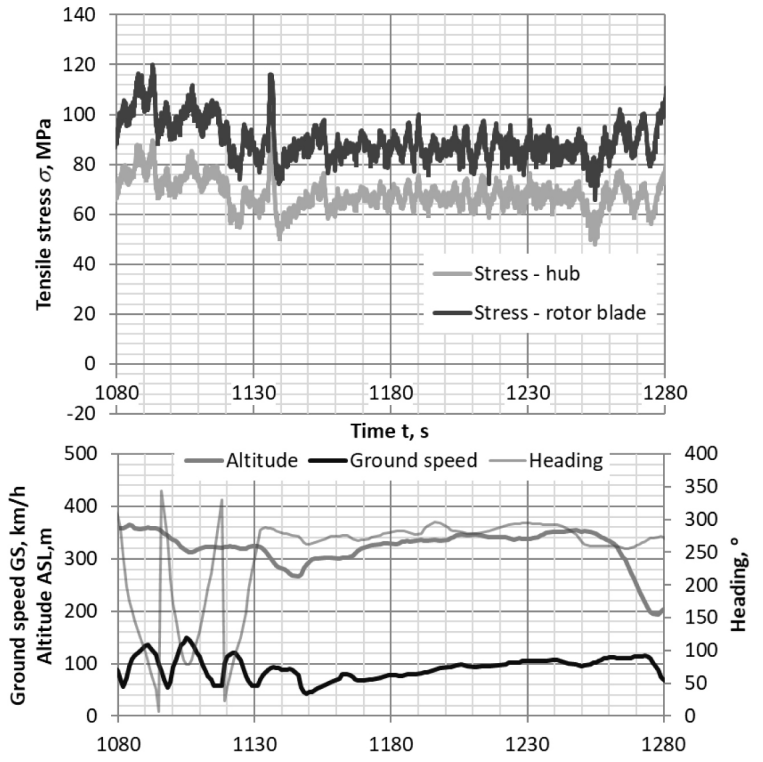

Fig. 14. Stresses against flight parameters at straight-and-level flight with moderate speed

The further element of the test consisted in slowly reducing the speed and ten performing a slow turn at increased forward speed (Figure 13). Between the $980^{\text {th }}$ and $1050^{\text {th }}$ second of the test, the flight was practically straight and level with the speed dropping steadily to $90 \mathrm{~km} / \mathrm{h}$. The stresses in the rotor blade and the hub bar stayed close to the stresses of the previous phase, with the means of $89.5 \mathrm{MPa}$ and $70 \mathrm{MPa}$, and the maximum values of 99.3

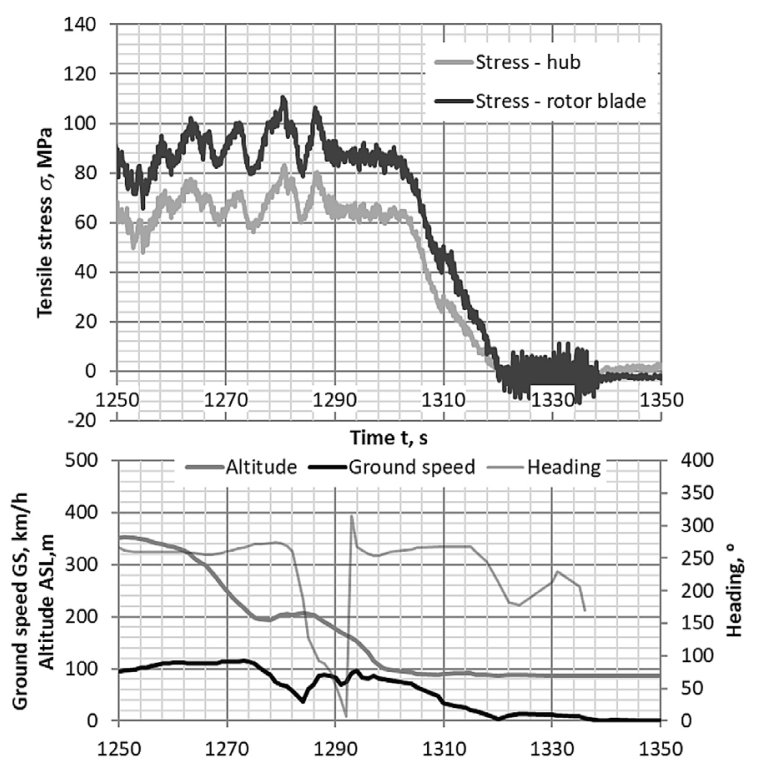

Fig. 15. Stresses against flight parameters at landing and taxiing 
$\mathrm{MPa}$ and 79.2 MPa, respectively. Between the $1080^{\text {th }}-1100^{\text {th }}$ second of the test, a U-turn was performed with the rate of $15 \mathrm{deg} / \mathrm{s}$, and with a drop of speed and altitude to maintain the kinetic energy of the rotor. In the course of the U-turn, the stresses in the rotor grew as a result of associated centrifugal forces. The maximum stress reached 119.3 MPa in the rotor blade and 88.2 MPa in the hub bar. The mean values were, respectively, $97 \mathrm{MPa}$ and $76 \mathrm{MPa}$.

The next element of the test was again a straight-and-level flight, this time at a constant speed of about $100 \mathrm{~km} / \mathrm{h}$ (Figure 14). As in the case of previous phases of flying with a constant heading and constant altitude, the mean stress during this period (between the $1150^{\text {th }}$ and the $1250^{\text {th }}$ second) stabilized at a moderate level of 91 $\mathrm{MPa}$ for the rotor blade and $68 \mathrm{MPa}$ for the hub bar. The stresses did not exceed $101 \mathrm{MPa}$ (rotor blade) and $78 \mathrm{MPa}$ (hub bar).

The final stage of the test comprised landing and taxiing (Figure 15). Between the $1260^{\text {th }}$ and the 1280 second, the aircraft was brought to a descent solely by adjusting the rotor disc attitude. This maneuver was conducted more gently than in the previous case of a steep descent (the $810^{\text {th }}-860^{\text {th }}$ second, Figure 11); therefore, the increase in rotor stress was smaller: the maximum observed values were 109.8 $\mathrm{MPa}$ in the rotor blade and $82.3 \mathrm{MPa}$ in the hub bar. After reaching the altitude appropriate for the final approach (second 1280), the last turn was made to align with the runway. The engine power was reduced and the aircraft descended to touchdown (between $1285^{\text {th }}$ and $1300^{\text {th }}$ second). During this period, the rotor stresses were stable and their values corresponded to those at the straight-and-level flight. After touchdown on second 1300 , the rotor speed was reduced (the stresses drop). On second 1320, the rotor stopped completely, and the stresses were due to the rotor blade swinging as the aircraft taxied along the uneven airstrip.

\section{RESULT ANALYSIS}

The first step was to analyze the distribution of the rotor stress recorded during the whole experiment. Figure 16 presents the tensile stress histograms for the rotor blade and the hub bar. Clearly, the distributions are bimodal. The first concentration of results occurs around $0 \mathrm{MPa}$ (low

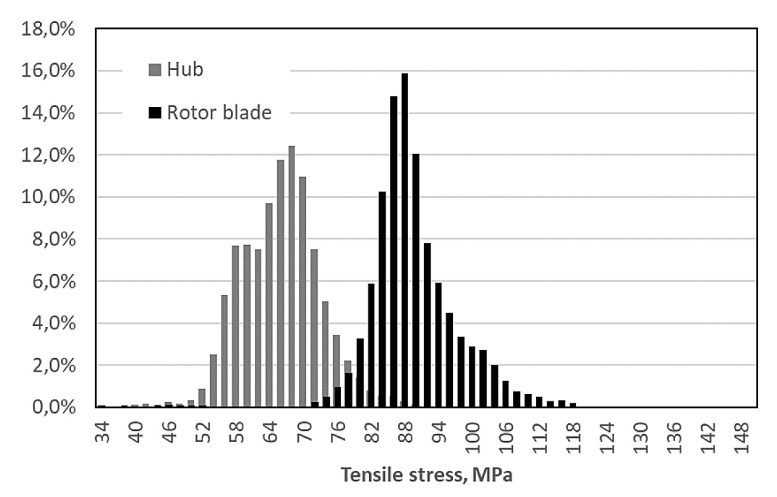

Fig.17. Histograms of the rotor blade and the hub bar tensile stress in flight

stresses during the preparation for flight, taxiing, preparation for take-off, and taxiing after landing, as these operations have a considerable share in the test duration). The other peak corresponds to high stress during most of the maneuvers in the air. The transition phase is practically negligible in terms of frequency of occurrence.

The actual flight (the air phase of the test), shown in Figure 17, is worth an individual consideration. The hub bar stress ranged from 52 to $88 \mathrm{MPa}$, and its median was $66.1 \mathrm{MPa}$. As for the rotor blade, the range of stress values was broader (72-119 MPa) with a median of $89.3 \mathrm{MPa}$.

The next part of the analysis relates the stresses to the flight parameters. Figure 18 presents the relationship between the stress and the altitude. The fact that greater rotor blade and hub bar stresses were recorded at higher altitudes was not the results of the altitude actually affecting the rotor load, but from the fact that most maneuvers were performed higher above the ground for safety reasons. In the case of this particular test,

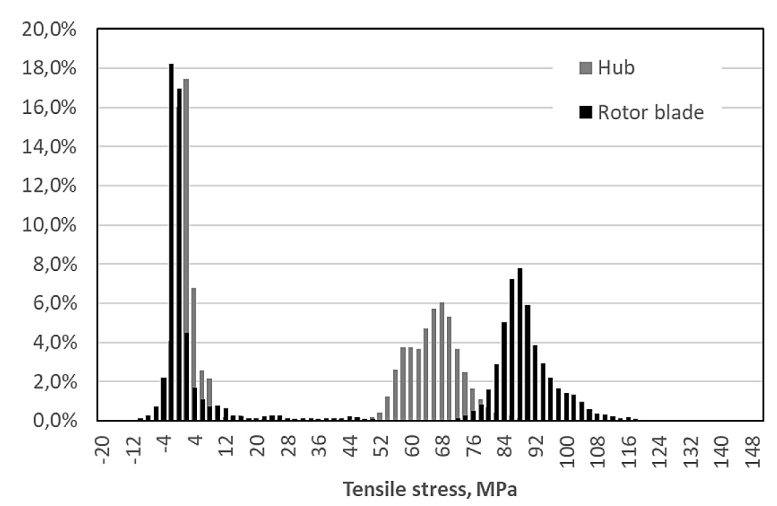

Fig. 16. Histograms of the rotor blade and the hub bar tensile stress over the entire test 


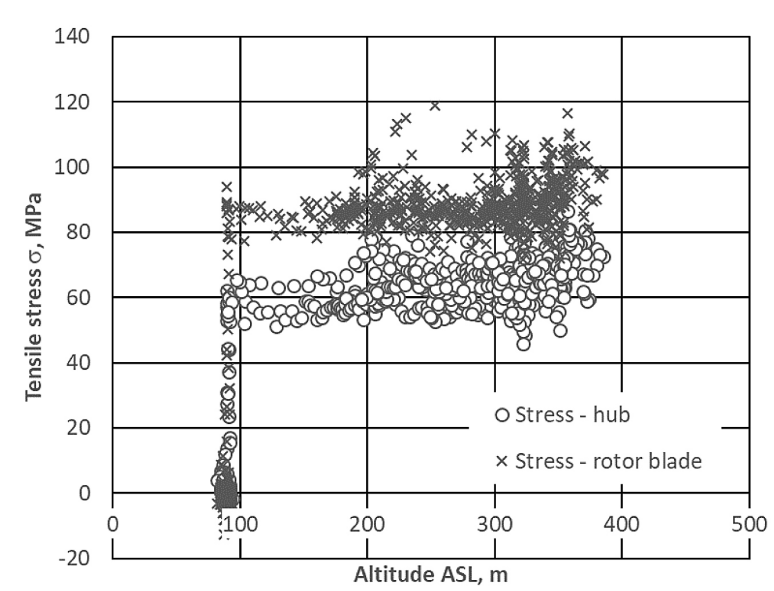

Fig. 18. Rotor blade and hub bar tensile stress vs. altitude

conducted in the range of 90-400 $\mathrm{m}$ above the sea level, the effect of altitude was insignificant.

As illustrated by Figure 19, the greater the ground speed, the higher the mean stress in the rotor. In the case of the rotor blade, the difference in the mean stress at the ground speed of $50 \mathrm{~km} / \mathrm{h}$ and $170 \mathrm{~km} / \mathrm{h}$ was $7 \mathrm{MPa}$. For the hub bar, the same speed difference corresponded to the mean stress raising by $10 \mathrm{MPa}$. This is most likely due to an increase in airflow velocity around the blades.

Figure 20 shows the relationship between the stresses and the aircraft's vertical speed. The vertical speed was calculated on the basis of changes in the altitude. The vertical speed practically does not influence the rotor stresses: the stress distribution is practically symmetric about the vertical axis.

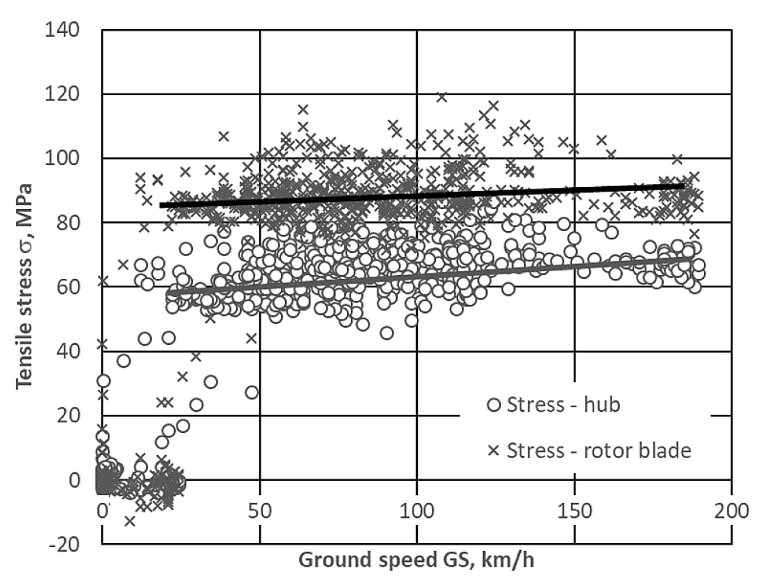

Fig. 19. Rotor blade and hub bar tensile stress vs. ground speed

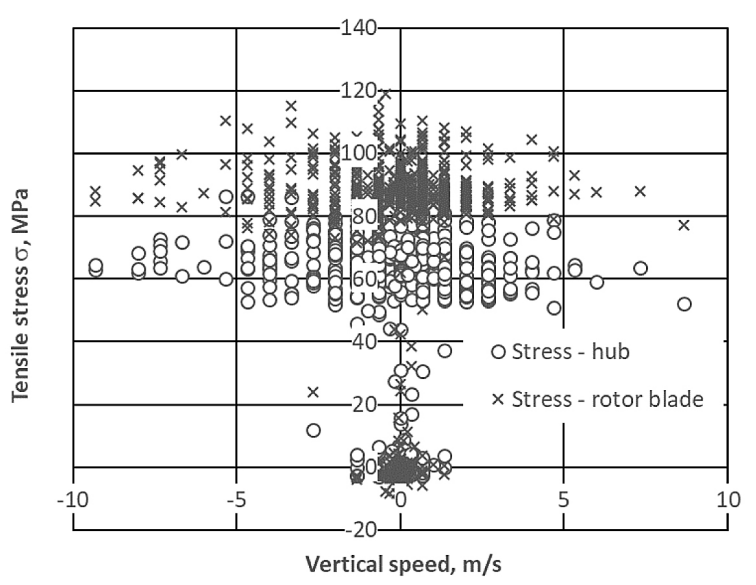

Fig. 20. Rotor blade and hub bar tensile stress vs. vertical speed

The aircraft's horizontal acceleration seemed to have little effect on tensile stresses in the hub bar and the rotor blade (Figure 21). The calculation of horizontal acceleration based on changes in the ground speed. The pattern of distribution of stresses against horizontal acceleration was, in general, similar to the pattern of stress vs. vertical speed: symmetrical about the vertical axis. However, attention should be paid to the upper left corner of the graph: the maximum stresses in both the rotor blade and the hub bar are related with strong deceleration in the forward motion of the aircraft. These cases correspond to the maneuver of decelerating by using rotor drag (the test phase illustrated by Figure 11). Therefore, the greater tensile stress in the rotor is associated with slowing down by adjusting the rotor disc attitude.

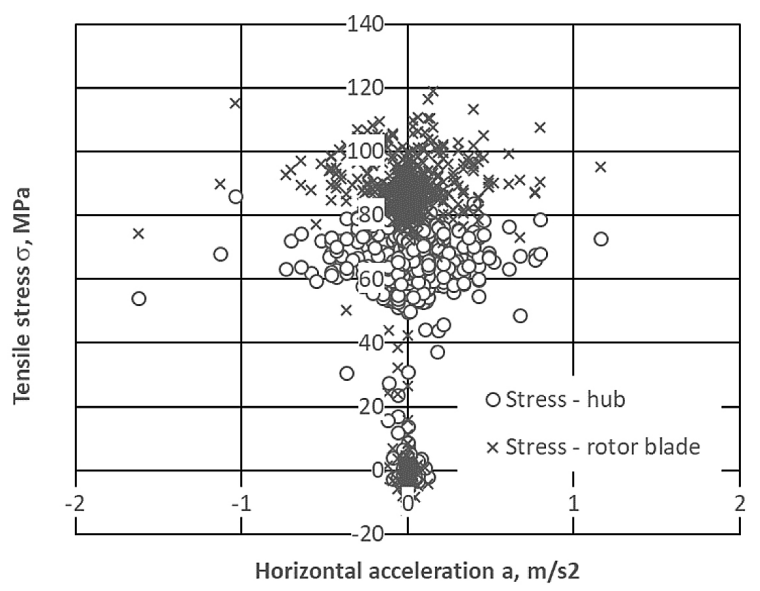

Fig. 21. Rotor blade and hub bar tensile stress vs. horizontal acceleration 


\section{CONCLUSIONS}

The in-flight test of tensile stresses in a gyroplane rotor provided insight into the effect of particular maneuvers on rotor loads. The test covered a full range of speed within the flight envelope of a particular model of a gyroplane loaded to its maximum take-off weight. The results justify the following conclusions:

1) Greater tensile stress was observed in the rotor blade than in the hub bar. The median stress values (during the aircraft in the air) were: 89.3 $\mathrm{MPa}$ in the rotor blade and $66.1 \mathrm{MPa}$ in the hub bar. These medians equaled the stresses observable during the straight-and-level flight at cruising speed.

2) The mean stress during the straight-and-level flight was stable and only slightly affected by the speed. An increase in flight speed resulted in growing stress, but an increase in speed from 50 to $170 \mathrm{~km} / \mathrm{h}$ changed the stress by only $7 \mathrm{MPa}$ in the rotor blade, and by $10 \mathrm{MPa}$ in the hub bar.

3) The maneuver associated with the greater rotor stress was found to be the deceleration by increasing the rotor disc's angle of attack, applied in steep descents and landings. The maximum stresses recorded in the case of this maneuver in the rotor blade and the hub bar were 120.6 $\mathrm{MPa}$ and $89.9 \mathrm{MPa}$, respectively.

4) It is therefore clear that the maximum stresses in the dynamic states are about 35\% higher than in the steady states. Therefore, an overload factor of 1.4 can be assumed for the design of new structures.

5) It should also be noted that, for the structure under test, the maximum stress value has approached the limit values significantly. This means that the structure has been designed correctly but has practically no margin of error for dispersion of material properties or manufacturing defects. Therefore, a control of the material supply during production is critical and the introduction of a maintenance inspection of the blade condition at the tested point is required.

The results are the basis for planning further experiments. The first scope of work to be carried out is to relate the stresses in the blade to the rotational speed of the main rotor and its angular accelerations. For this purpose, the whole envelope of the flight conditions should be re-examined by measuring both stresses and rotor speed. This will determine the effect of the centrifugal force on the stress value.

\section{Acknowledgements}

The research was financed in the framework of the project Lublin University of Technology - Regional Excellence Initiative, funded by the Polish Ministry of Science and Higher Education (contract no. 030/RID/2018/19)

\section{REFERENCES}

1. US. Departmente of Transportation Federal Aviation Administration, Rotorcraft Flying Handbook. 2000.

2. U.S. Department of Transportation Federal Aviation Administration, Helicopter Flying Handbook, vol. 1. 2012.

3. U.S. Department of Transportation Federal Aviation Administration, Aviation Maintenance Technician Handbook - Powerplant vol. 2, vol. 2. 2012.

4. Mil' M.L. et al., Helicopters - calculation and design Vol. 11. Vibrations and Dynamic Stability (NASA TT F-519), 1997.

5. S.A. Division, U.A. Corporation, and N. Aeronautics, Contractor report NASA CR-2225 analysis of helicopter maneuver-loads and rotor-loads flighttest data, by Edward A. Beno Sikorsky Aircraft Division United Aircraft Corporation, 1973.

6. Yeo H., Design and aeromechanics investigation of compound helicopters, Aerosp. Sci. Technol., vol. 88, pp. 158-173, 2019.

7. Gao H., A. He, Z. Gao, Y. Na, And Y. Deng, Flight dynamics characteristics of canard rotor/wing aircraft in helicopter flight mode, Chinese J. Aeronaut., vol. 32, 2019, 1577-1587

8. University of Twente, Smart helicopter thanks to active rotor blades, 2013.

9. Islam M.T., M. S. Rabbi, and M. S. Uddin, Noise reduction of helicopter rotor blades by using spoiler. In: AIP Conference Proceedings, 2019, vol. 2121.

10. Shi Y., T. Li, X. He, L. Dong, and G. Xu, Helicopter rotor thickness noise control using unsteady force excitation, Appl. Sci., vol. 9, no. 7, 2019.

11. Serafini J., G. Bernardini, R. Porcelli, and P. Masarati, In-flight health monitoring of helicopter blades via differential analysis, Aerosp. Sci. Technol., vol. 88, 2019, 436-443.

12. European Aviation Safety Agency, and Acceptable Means of Compliance for Light Sport Aeroplanes CS-VLR, ED Decision 2018/015/R, no. December, p. 76, 2018.

13. European Aviation Safety Agency, Certification specifications and acceptable means of compliance for Small Rotorcraft CS-27, ED Decision 2019/013/R, no. July, p. 225, 2019. 
14. Degu Y.M. and D. Alebel, Design of Composite Gyrocopter Main Rotor Blade Involving Rib and Spar Elements, vol. 9, no. 2, 2019, 97-106.

15. Reddy M., Aerodynamic Load Estimation of Helicopter Rotor in Hovering Flight, J. Aeronaut. Aerosp. Eng., vol. 05, no. 01, 2015, 1-5.

16. Stalewski W. and W. Zalewski, Performance improvement of helicopter rotors through blade redesigning, Aircr. Eng. Aerosp. Technol., vol. 91, no. 5, 2019, 747-755.

17. Pastrikakis V.A., R. Steijl, and G. N. Barakos, Effect of Active Gurney Flaps on Overall Helicopter Flight Envelope, Aeronaut. J., 2016.
18. Warwick G., Leonardo to Flight Test Active Rotor Blade, The Weekly of Business Aviation, 2016.

19. Han D., V. Pastrikakis, and G. N. Barakos, Helicopter flight performance improvement by dynamic blade twist, Aerosp. Sci. Technol., vol. 58, 2016, 445-452.

20. McCormick B.W., A numerical analysis of autogyro performance, in 2002 Biennial International Powered Lift Conference and Exhibit, 2002.

21. Gausz Z. and T. Gausz, Aeromechaincal model for gyroplane rotors, in Proceedings of the Mini Conference on Vehicle System Dynamics, Identification and Anomalies, 2012, Novem, 29-38. 